BAPL, 36. 2002 (181-189)

\title{
CELEBRACIÓN POR EL VIEJO Y EL MAR
}

\section{Carlos Eduardo Zavaleta}

Es esta noche de fiesta literaria, permítanme preguntarme en público: ¿qué habría sido de nosotros los lectores de Hemingway, e incluso de los críticos, si él no hubiese publicado El viejo y el Mar?

En pocas palabras, no contaríamos con el mejor libro de su carrera, el que por fin calmó la extraña ansiedad vivida, por ejemplo, en 1950, cumplidos diez años de su silencio, sin una obra de polendas, que enhebrara los éxitos innegables de Adiós a las armas, de Por quién doblan las campanas, y de sus cuatro espléndidas colecciones de cuentos de 1925 (In our time), 1927 (Men Without Women), 1933 (Winner Take Nothing), y 1938, con el gran volumen titulado Quinta columna y los primeros 49 cuentos, del cual han brotado tantas antologías parciales en español.

Pues bien, todo este conjunto de cuentos y novelas muy selectos tenía que seguir, en la apreciación crítica de entonces, el consabido prestigio de la novela por encima del cuento, prestigio que viene desde el siglo XVIII, y por ello se esperaba en el ambiente una nueva novela digna de las grandes posibilidades de Hemingway. Sin embargo, justamente ese año de 1950, aparece A través del río y entre los árboles, que no podía 
satisfacer tantas expectativas. Así, la crítica fue dura, mordaz y aun carnicera. Algunos mezquinos dijeron que el maestro estaba acabado.

Por ello, la súbita y espectacular difusión mundial de $E l$ viejo y el mar cambió el balance de las cosas; satisfizo por completo en Europa, Estados Unidos, y aun en América Latina, por los sólidos lazos con Cuba, y los aplausos dejaron a Hemingway en las puertas del Premio Nobel, que ganó en 1954, pese a que pocos años antes, William Faulkner, otro norteamericano, había recibido igual galardón. Merecido homenaje mundial para la llamada "generación perdida", con los nombres señeros de Gertrude Stein, Fitzgerald, Dos Passos, Faulkner, Hemingway, James T. Farrel, Thomas Wolfe y John Steinbeck. Jamás antes la novela norteamericana había tenido tantos maestros.

Pero volvamos a la época de ansiedad y desconcierto, a 1950, cuando aparece, luego de enorme espera, A través del río. El libro no podía satisfacer desde el punto de vista político (el pintoresco protagonista, el coronel Cantwell, zahiere incluso a héroes nacionales como Eisenhower, Montgomery y Patton, y solo Bradley queda indemne), ni tampoco desde el punto de vista estilístico, pues aquí Hemingway sólo amplía innecesariamente sus diálogos; sus frases cortas y precisas se pierden en ese mar elefantiásico, y la trama del viejo militar resentido y celoso de sus colegas carece de escenas significativas y dramáticas. Lo único bueno que repite y ha repetido desde joven es su elección del fracaso como lección humana, una lección propia de la tragedia griega.

Así, su mejor obra conjunta es resultado del vínculo de los primeros cuentos, de sus mejores novelas cortas, como "Las nieves de Kilimanjaro" y "La corta vida feliz de Francis Macomber", y por fin el vínculo con Adiós a la Armas y Por quién doblan las campanas. Aquí están, o bien el juvenil Nick Adams cuyo aprendizaje acabará en una lección trágica, o bien el gángster de "los Asesinos", un hombre estoico, un 
héroe digno a su modo, desafiado por la Muerte con mayúscula y no por los miserables bandidos que lo acaban. Ahí está, asimismo, el ejemplo de "El invicto", el torero sin ganas de jubilarse y que vuelve al ruedo para alcanzar lo que él sabe, una victoria fugaz, antes de marcharse a las sombras. Sí, las sombras, dignas de Shakespeare, absorben a varios de sus héroes, incluso a Roberto Jordan, que puede parecer ingenuo en sus modales y diálogos pero conectado ya para siempre con el amor y la muerte, y todavía más, con la lucha de todo un pueblo por su libertad.

Dicho esto, enfoquemos el mérito real y fascinante de Hemingway. Es su estilo, por supuesto, la frase breve, lacerante, emotiva o gélida, pero siempre oportuna e insustituible. Y en torno a sus frases cortas, la búsqueda del párrafo igualmente incisivo, y muy gradual, ya sea en el tema o en la excitación del lector. El autor ama en la prosa los sustantivos, que son las palabras mejor prendidas y apegadas a las cosas, o quizá las cosas mismas, y con el sustantivo va el soporte de algunos verbos y sus gerundios, no de muchos (recordad que Faulkner dijo que para leer a Hemingway no se necesita diccionario alguno), y así este estilo sustantival precisa sólo de indispensables adjetivos para incitar y excitar al lector, a quien por supuesto ha cogido del cuello para no soltarlo sino al final, según los deseos de lograr el efecto único de Edgard Allan Poe, pero con la ventaja de la suprema brevedad y concisión.

En cuanto a sus temas, desplegados siempre en tramas sugerentes, hay el antecedente histórico de la aventura, la vivencia inolvidable, casi siempre acompañada de un escenario singular, aventura descrita por James Fenimore Cooper, por Mark Twain y Jack London. Aquí está su apego a la gente del pueblo, al hombre parecido a muchos hombres, y cuyo paso por la vida puede ser una fugaz victoria sobre los peligros y la muerte. He aquí, en suma, lo que Wyndham Lewis llamó "el estilo de la realidad", pero infinitamente complejo, pues se trata de una reconstrucción parcial, interesada, caprichosa; pero más significativa que la propia realidad. 
A fin de explicarlo aún más, el escritor y crítico británico H. E. Bates goza viendo a Hemingway en un bosque, hacha en mano, tirando abajo los troncos del idioma inglés para hacerlo más útil y puro, limpiándolo de frases sin significado y de vacuas discusiones sociológicas y moralizantes, desde la época de Dickens. En vez de los troncos derribados, Hemingway nos da un contacto directo entre el objeto y el ojo, entre el lector y el objeto. ¡Afuera la verbosidad, las frases indirectas, elegantes y académicas, afuera los clichés muertos y sagrados, afuera las convenciones del débil mecanismo del diálogo antiguo!

El gran maestro de Harvard y Berkeley, Harry Levin, estudió cómo se trasmiten al lector la excitación y lo concreto, mediante la expresión de detalles, el poco uso de adjetivos y verbos, y la tendencia a inmovilizar éstos transformándolos en gerundios. Pese a la dicción nada rica y a la sintaxis débil, el poder del estilo de Hemingway consiste en una secuencia de movimientos y hechos, una escritura lineal sin complicaciones estructurales, buscando la llamada "exaltación del instante", según frase feliz de la francesa Claude Edmonde Magny. La paradoja entre su rudeza y la notable sensibilidad se explica por una visión poética, que renueva nuestro contacto interrumpido con los elementos duraderos de la existencia humana: el pan, el vino, el árbol, el amor, la música, el peligro y unas pocas cosas concretas y universales. Levin insiste en que el autor comunica una excitación, y si se recibe ésta, ella es un lazo personal con el lector. Hemingway se mantiene en el ámbito de lo concreto, inclusive cuando escribe oraciones negativas, donde el personaje no hace lo que él mismo espera.

Según otro novelista inglés, David Herbert Lawrence, los cuentos de Hemingway son excelentes, y tan cortos como si frotáramos un fósforo y encendiéramos un cigarrillo fantástico, y luego no hay nada. En suma, Hemingway no reconoce valores excepto los que pueden ser inmediatamente sentidos y directamente señalados. A su excepticismo verbal algunos críticos lo han liamado su nihilismo moral. Durante la lectura, 
no puede haber división entre el actor y el espectador, he ahí el secreto de su vitalidad.

Respecto a la atmósfera de violencia, miedo, coraje y muerte, André Maurois señaló hace tiempo la angustia que emerge casi naturalmente de la biografia de Hemingway. Sus personajes se imponen reglas caprichosas e inviolables, pero no necesariamente morales; y su conducta para con la mujer es semejante a la de Kipling, para quien aquélla era a la vez un obstáculo y una tentación. En el mundo moderno y convulso en que vivimos, esa angustia puede haberse profundizado.

En fin, todas estas virtudes de los textos breves, de las novelas cortas, y de dos novelas largas (Adiós a las armas y Por quién doblan las campanas), se reúnen, se magnifican, en El viejo y el mar, como por ejemplo, la descripción ubicua, que incluso engloba paisajes, pero que de algún modo sigue siendo sintética y precisa, la evocación nostálgica, la ironía, el contraste, los mundos paralelos entre la realidad, la esperanza, la frustración y otra vez la esperanza y la frustración, en un ritmo más o menos inacabable.

$\mathrm{Y}$ además de estas nuevas virtudes, el autor aplica de modo más frecuente que antes el esquema de Joyce, que repite de muchos modos el contrapunto entre el mundo objetivo y el subjetivo, que empieza describiendo la situación actual, luego del diálogo, después el pensamiento íntimo y callado, o sea el monólogo interior, y finalmente se vuelve a la situación actual, cerrando un círculo y enlazando con el núcleo siguiente, y así llenando las páginas de descripciones, de impresiones, de diálogos, de monólogos, y de la nueva situación actual que indica el movimiento no sólo físico del personaje sino su vida mental, la cual refleja por supuesto el panorama social, el lugar, la época y aun las costumbres, ideas o mitos en que se vive.

Pongamos un fácil ejemplo en que se suceden los cuatro pasos estilísticos anotados ${ }^{1}$ :

Ernest Hemingway, El Viejo y el mar (Buenos Aires: Kraft, 1954), p. 144. 
El viejo se puso al timón. Ni siquiera quiso ver cómo el tiburón se hundía lentamente en el agua, apareciendo primero en todo su tamaño; luego pequeño; luego diminuto. Eso le había fascinado siempre. Pero ahora ni siquiera miró.

- Ahora me queda el bichero - dijo—. Pero no servirá de nada. Tengo los dos remos y la caña del timón y la porra.

Ahora me han derrotado, pensó. Soy demasiado viejo para matar los tiburones a garrotazos. Pero lo intentaré mientras tenga los remos y la porra y la caña.

Puso de nuevo sus manos en el agua para empaparlas. La tarde estaba avanzando y todavía no veía más que el mar y el cielo. Había más viento en el cielo que antes y esperaba ver pronto tierra.

Este esquema estilístico, que puede crecer o disminuir a voluntad, se comprende mejor cuando en él se inserta la simbólica lucha entre el hombre y la naturaleza, el hombre y el animal (el incomprendido y supuestamente maligno en la pugna civilizadora de la humanidad), lucha milenaria y que en Estados Unidos ostenta como tradición Moby Dick, de Melville; Open Boat, de Bret Harte; y "El oso" de Faulkner.

Respecto de la línea argumental, por lo general da dos o tres giros inesperados, sorprendentes y luego enfila hacia el remate, como si éste fuera el signo emblemático de la fatalidad, cuando vencen las fuerzas sobrehumanas, o quizá, únicamente las sombras y el misterio.

Para Philip Young, Hemingway es el más grande estilista norteamericano, sólo comparable a Henry David Thoreau, el autor de la autobiografía Walden (1854) y de su ensayo Sobre el deber de la desobediencia civil (1849). Ya menos enfático, dijo luego que si Faulkner y Eliot están en un primer estante de libros, deberían hacerle un espacio a Hemingway.

Y en fin, antes de concluir, referiré dos anécdotas sobre este tema del estilo de Hemingway, que es principal para mí. 
La primera enlaza sus escritos con su actividad periodística. Sin duda muchos de nosotros tenemos algún recorte inesperado sobre los artículos del autor. Yo deseo destacar un despacho del periodista español Francisco Basterra, enviado desde Wáshington al diario El País (Madrid, 10 de setiembre de 1988), sobre cómo, por fin, el profesor norteamericano William Watson halló treinta crónicas enviadas por Hemingway sobre la guerra civil española, cobrando 500 dolares por pieza. Todas aparecen en el número de la Hemingway Review, de tal año de 1988. Ahora sabemos que el famoso estilo de frases breves, cortantes, de muchos sustantivos, pocos verbos y menos adjetivos, se transmitía telegráficamente (es decir, ya abreviado por el autor), pero con nuevas e incorrectas abreviaturas (los telegrafistas españoles ignoraban el inglés), o también uniendo indebidamente palabras (menester muy natural por ese medio de trasmisión), y las crónicas viajaban vía Madrid, Londres, Nueva Escocia (el Canadá) y Nueva York, donde la agencia NANA (North American News Alliance), sin respetar mucho los escritos de su corresponsal, los corregía y publicaba a voluntad. Pues bien, Watson ha logrado, a partir de fragmentos y del enorme conocimiento que tiene de frases y giros del autor, reconstruir esos artículos y los ha comparado con los originales que él finalmente obtuvo de archivos y bibliotecas. Alegrémonos, pues, que ni las abreviaturas, ni los errores telegráficos, ni las supresiones ni añadidos de palabras pudieron desnaturalizar un estilo que sin duda se halló en armazón, en esqueleto, y se reconstruyó como a los órganos de un nuevo animal literario, recompuesto en el laboratorio. Cuando alguien tiene un lenguaje, una marca de león en el papel, ésa no la destruye por completo nadie.

Y la segunda anécdota es mucho más cercana al Perú y a nosotros los amigos del gran poeta y escritor Sebastián Salazar Bondy. Allá por 1954 (en pleno auge del ambiente formado en torno al último libro de Hemingway vivo, digo, de El viejo y el mar, y del prestigio de su obra anterior), Sebastián 
publicó su primer libro de cuentos Náufragos y sobrevivientes $^{2}$. Ahí hay un cuento poco estudiado y mal recordado. Se titula curiosamente "La navaja automática", título extraño en un intelectual poco dado a hechos de sangre. Pues bien, si cotejamos ese texto con aquel otro tan elogiado y personalísimo de Hemingway, como es "La capital del mundo" (texto que aparece en segundo lugar en su magistral antología de cuentos de $1938^{3}$ ), nos daremos con semejanzas de tema, de tratamiento, y sobre todo de paso de una situación alegre, burlona, de un juego entre dos camareros de cafetería en Madrid, a otra inesperada, pues luego de una gran tarde de toros, oída por ellos, ni siquiera vista, y cuando están limpiando el local y poniendo sillas sobre las mesas, se sienten con deseos de comentar las faenas, y juegan primero con las sillas patas arriba, hasta que de la diversión y las risas se pasa al hormigueo del desafío, de la valentía puesta a prueba, y uno de ellos ata un gran cuchillo a una pata de silla, y ahora vemos una lucha simbólica entre el toro y el torero, y la mentira provoca a la verdad tanto, que el episodio termina con la sangre fraterna pero ya derramada irreductiblemente.

Así, en el cuento de Sebastián, un muchacho bohemio sigue la "onda", la moda turbia y peligrosa de Lima, y compra en una tienda del centro una navaja automática porque sí, pues no la necesita, y va al cafetín, a su grupo de bohemios y bebedores inocentes, donde todo nace en diversión y sonrisas, pero donde un malgeniado salta de cólera como si la cosa fuera con él, y en un primer paso de la diversión hacia el juego de villanos, lo desafía abiertamente con una hoja de gillete, sí, con una hoja de gillete, pues se cree muy hombre y al otro un cobarde y tonto, y le grita y jaquea varias veces, hasta que un inocente ofendido acepta el desafío y la navaja cumple su misión y el inocente acaba en criminal, que será pronto capturado por la policía.

Sebastián Salazar Bondy, Náufragos y sobrevivientes (Lima: Círculo de novelistas peruanos, 1954).

3 Ernest Hemingway, The Short Stories (New York: Scribner's Sons, 1938), pp. 38-51. 
La línea narrativa da, pues, un giro súbito e inesperado, y lo que es blanco se vuelve negro y llega la tragedia.

Pero el cuento de Sebastián no es una copia ni nada de eso, es una aplicación personal de un tema cuyo hilo cambia de dirección, sin explicación alguna, como si el destino de los hombres, y no ningún hombre, lo hubiera dispuesto así.

Y pongo el texto de Sebastián como un ejemplo, que no es el único, en un país que ha admirado y leído con devoción al forzudo con cara de león y alma de niño y de joven, siempre prendido del pecho de su padre, vivo o muerto. 